\title{
Assessment and Implementation of an Interdisciplinary General Education Minor
}

\section{Kirsten A. Davis, Virginia Tech}

Kirsten is a PhD student in Engineering Education at Virginia Tech, where she also completed her master's degree in Higher Education. She has previously worked in industry in the field of IT analytics and has experience with corporate recruiting. Her primary research interests are engineering study abroad, developing intercultural competency in engineering students, and international higher education.

\section{Chris Gewirtz, Virginia Tech}

Graduate Student in Engineering Education at Virginia Tech. His research interests include: engineering for social justice, engineering with community, innovation, ethics, transformative learning, reflection, professional identity.

\section{Mr. Ramon Benitez, Virginia Tech}

Ramon Benitez is interested in how engineering identity and animal participatory design can be used to recruit Chicano K-12 students to engineering professions. Benitez completed his BS in Metallurgical and Materials Engineering at the University of Texas at El Paso (UTEP), and is now a Ph.D. student in Engineering Education at Virginia Tech (VT). Benitez seeks to understand how to best instruct and assess ethical reasoning of engineering practices and engineering responsibilities, including wildlife and humanity, in our definitions of public good.

\section{Dr. Lisa D. McNair, Virginia Tech}

Lisa D. McNair is an Associate Professor of Engineering Education at Virginia Tech, where she also serves as co-Director of the VT Engineering Communication Center (VTECC) and CATALYST Fellow at the Institute for Creativity, Arts, and Technology (ICAT). Her research interests include interdisciplinary collaboration, design education, communication studies, identity theory and reflective practice. Projects supported by the National Science Foundation include exploring disciplines as cultures, liberatory maker spaces, and a RED grant to increase pathways in ECE for the professional formation of engineers. 


\section{Assessment and Implementation of an Interdisciplinary General Education Minor}

\section{Introduction}

General education, also known as liberal education, is argued to be a key component of higher education as it develops the breadth of knowledge and skills individuals need to thrive in a complex society. ${ }^{1}$ However, as a utilitarian view of higher education gains ground, general education has come under threat, particularly for engineering degrees, which comprise more credits than most. Balancing the competing purposes of professional and liberal education introduces challenges at the university level, particularly at schools housing a variety of degree programs. These challenges to liberal education make it essential that general education programs be assessed against the outcomes that proponents argue justify their inclusion in higher education. Assessment offers a chance to demonstrate the benefits of general education based on data collected to measure stated learning outcomes. ${ }^{2}$

Assessment often faces a negative stigma suggesting that it can only be used for casting judgment on specific faculty members, courses, or programs. On the contrary, however, assessment can be used as a method of process improvement to ensure that desired goals and learning outcomes are met, including progressive pedagogical approaches and initiatives. Suskie suggests a teaching-learning-assessment cycle that highlights the iterative nature of assessment. ${ }^{3}$ In each iteration of the cycle, faculty or university administrators can use the results of the previous round of assessment to improve the course or program being assessed. In this view of assessment, change is incremental and realistic; perfection is not expected or achieved. Rather, assessment allows educational designers to practice continuous improvement by providing data with which they can make informed decisions about what to adjust in future iterations of a course or program.

Taking this view of assessment, the authors of this paper have conducted one iteration of an assessment cycle with three courses that form the core sequence of a new interdisciplinary general education minor housed in an engineering department at Virginia Tech. The purpose of this paper is to introduce the format of a new general education initiative at Virginia Tech, describe our assessment process and results, and discuss how our initial assessment will inform future iterations of the assessment cycle. In our description of this project, we highlight the potentially productive tension between curriculum design and assessment in an environment of institutional change.

\section{Background}

General education is often structured in a "checklist" format, where students need to complete a prescribed number of credits in each of several categories. Virginia Tech has used such a system for many years, but recently recognized several weaknesses of this model. First, most students lack intentionality in their selection of courses to meet each requirement, choosing mainly based on which courses fit into their schedules or are known to be easy. This often results in a series of unrelated courses that students do not find relevant nor connect back to their major in meaningful ways. Second, courses offered in this model tend to be at the 1000-2000 
level only, meaning that students only have the opportunity to get a surface-level taste of a topic before needing to move on to something else to fulfill a different requirement. To address these concerns, Virginia Tech is in the process of introducing a new structure for general education called Pathways to General Education. In the new model, students are able to choose from multiple Pathways that allow them to meet the general education requirements.

One new option for students within the Pathways model will be choosing an interdisciplinary minor designed to meet several of the general education core outcomes. This option addresses the concerns discussed above by giving students the chance to achieve their general education requirements while taking courses that are connected in an intentional way. These courses will also build on each other and allow students to delve deeper into the topic area of the minor, taking a few 3000-4000 level courses and a capstone by the end. Minors fitting these characteristics did not exist at Virginia Tech when the Pathways model was first announced, so a development phase has been underway for the past two years. In order to promote progressive curriculum design, faculty members from all departments were invited to apply for grants to develop Pathways minors, including designing new courses, reworking existing courses, and developing assessment strategies at both course and program levels. At the same time, the Pathways program requires that each minor assess the specific general education learning outcomes that the minor covers. In addition, all minors must assess two integrated learning outcomes: ethical reasoning and intercultural and global awareness.

One minor that is under review for inclusion in the Pathways program is the Innovation Pathways Minor (IPM). This minor was developed by connecting three existing courses on the topic of innovation into a progressive sequence that meets three of the general education learning outcomes. In addition to these core courses, students will select from a list of innovation-related electives to help meet other core outcomes in the general education curriculum. At the end of the minor, students will take a reflective one-credit capstone course simultaneously with the capstone course for their major. If they do not have a capstone course for their major, a threecredit capstone design course within the minor will be required. Although the IPM is housed in a department in the College of Engineering, it is open to all students and spans three colleges for the core courses and many more when considering the elective options. The minor requirements and short descriptions of the core courses are shown in Table 1.

Table 1. IPM course descriptions.

\begin{tabular}{|l|l|l|l|}
\hline \multicolumn{1}{|c|}{ Course Name } & \multicolumn{1}{|c|}{ College } & \multicolumn{2}{c|}{ Core Outcome } \\
\hline $\begin{array}{l}\text { Innovation in } \\
\text { Context }\end{array}$ & Liberal Arts & $\begin{array}{l}\text { Critical Thinking in } \\
\text { the Humanities }\end{array}$ & $\begin{array}{l}\text { Uses readings, discussion and course projects to } \\
\text { help students define innovation and consider } \\
\text { what it means to be an innovator }\end{array}$ \\
\hline Create! & Engineering & $\begin{array}{l}\text { Critique \& Practice } \\
\text { in Design \& Arts }\end{array}$ & $\begin{array}{l}\text { Guides students through a process of inquiry, } \\
\text { design, and collaboration to complete an } \\
\text { interdisciplinary design project }\end{array}$ \\
\hline StartUp & $\begin{array}{l}\text { Business/ } \\
\text { Design/ } \\
\text { Engineering }\end{array}$ & $\begin{array}{l}\text { Reasoning in the } \\
\text { Social Sciences }\end{array}$ & $\begin{array}{l}\text { Gives students the opportunity to work on real } \\
\text { world innovation commercialization projects } \\
\text { through the business model canvas process }\end{array}$ \\
\hline
\end{tabular}




\begin{tabular}{|l|l|l|l|}
\hline $\begin{array}{l}\text { Reflective } \\
\text { Capstone }\end{array}$ & Engineering & N/A & $\begin{array}{l}\text { Guides students in reflecting on their work in } \\
\text { innovation through constructing an ePortfolio; } \\
\text { taken simultaneously with a capstone design } \\
\text { course }\end{array}$ \\
\hline $\begin{array}{l}\text { Design } \\
\text { Capstone }\end{array}$ & $\begin{array}{l}\text { Engineering/ } \\
\text { Various }\end{array}$ & $\begin{array}{l}\text { Critique \& Practice } \\
\text { in Design \& Arts }\end{array}$ & $\begin{array}{l}\text { Incorporates all skills learned in the minor in a } \\
\text { team project }\end{array}$ \\
\hline
\end{tabular}

A pervasive challenge of developing a minor like the IPM is communicating clearly across disciplines. Because the IPM core sequence includes courses from three different colleges, the faculty teaching these courses have had to work closely to negotiate terminology and outcomes throughout the minor. One example of this is the term "design," which can be viewed differently between departments, especially between engineering and the arts. Because the goal of general education and the Pathways program is to encourage interdisciplinary thinking, it is important that each department allow for variation in how this term is used. While we did not attempt to settle on a single definition of design, the faculty have worked to be clear what they mean when they use this term in each course and when discussing the minor as a whole. This topic came up again when the minor went up for approval in the College of Engineering, and ultimately the college acknowledged that learning about different types of design would be beneficial for engineering students, just as teaching engineering design ideas to other majors would also benefit them. Interdisciplinary work is a process requiring adaptation and continual revision to personal perspectives to achieve integration between the different fields contributing to a project. ${ }^{4}$ This has been true in the process of developing the IPM and will continue to be necessary as the faculty members involved assess and adapt the minor going forward.

While the Pathways program invited the development of new courses, in reality few faculty members have the bandwidth to complete such a task while also assembling a new minor. As a result, most faculty focused on either developing a course or combining existing courses into a minor. Some faculty took the university initiative as an opportunity to formalize courses they had been teaching "under the radar." For example, two of the IPM required courses are based on interdisciplinary classes that faculty had taught as an overload because institutional structures only allowed work to be credited toward a single department. ${ }^{5}$ This reality means that the core courses of the IPM were not originally designed with the new general education learning outcomes in mind. This kind of process is counter to the teaching-learning-assessment cycle proposed by Suskie, in which learning outcomes should ideally guide the design of a course. ${ }^{3}$ Keeping in mind that reality rarely achieves perfection, the designers of the IPM decided that the best course of action to address this challenge would be to conduct one iteration of assessment on the three core courses even as the minor was under development by faculty instructors. This initial iteration would form a baseline or snapshot of where we are starting with relation to the learning outcomes we are required to meet, allowing us to begin the process of continuous improvement as soon as possible.

\section{Academic Planning, Interdisciplinarity, and Innovation in General Education}

As we brought the faculty and assessment teams together in this environment of institutional change, we turned to Lattuca and Stark's academic planning model, which conceptualizes 
curricula as academic plans that are developed and implemented within a larger sociocultural context. ${ }^{6}$ This framework guided the effort to bring together previous interdisciplinary curricula with new, measurable learning outcomes centered on the concept of innovation. In this section we review Lattuca and Stark's model and how it intersects with our goals of building an interdisciplinary minor in innovation.

\section{Using the Academic Planning Framework}

Lattuca and Stark forge a shared language out of the varying definitions of curriculum that faculty and administrators follow, taking into account the complex array of interacting elements that merit deliberate attention when designing courses and programs. ${ }^{6}$ Although academic plans are situated within a specific educational environment, they are influenced by external and internal factors and stakeholders that form a complex sociocultural context. A diagram of the framework is shown in Figure 1 and a description of several of the elements follows.

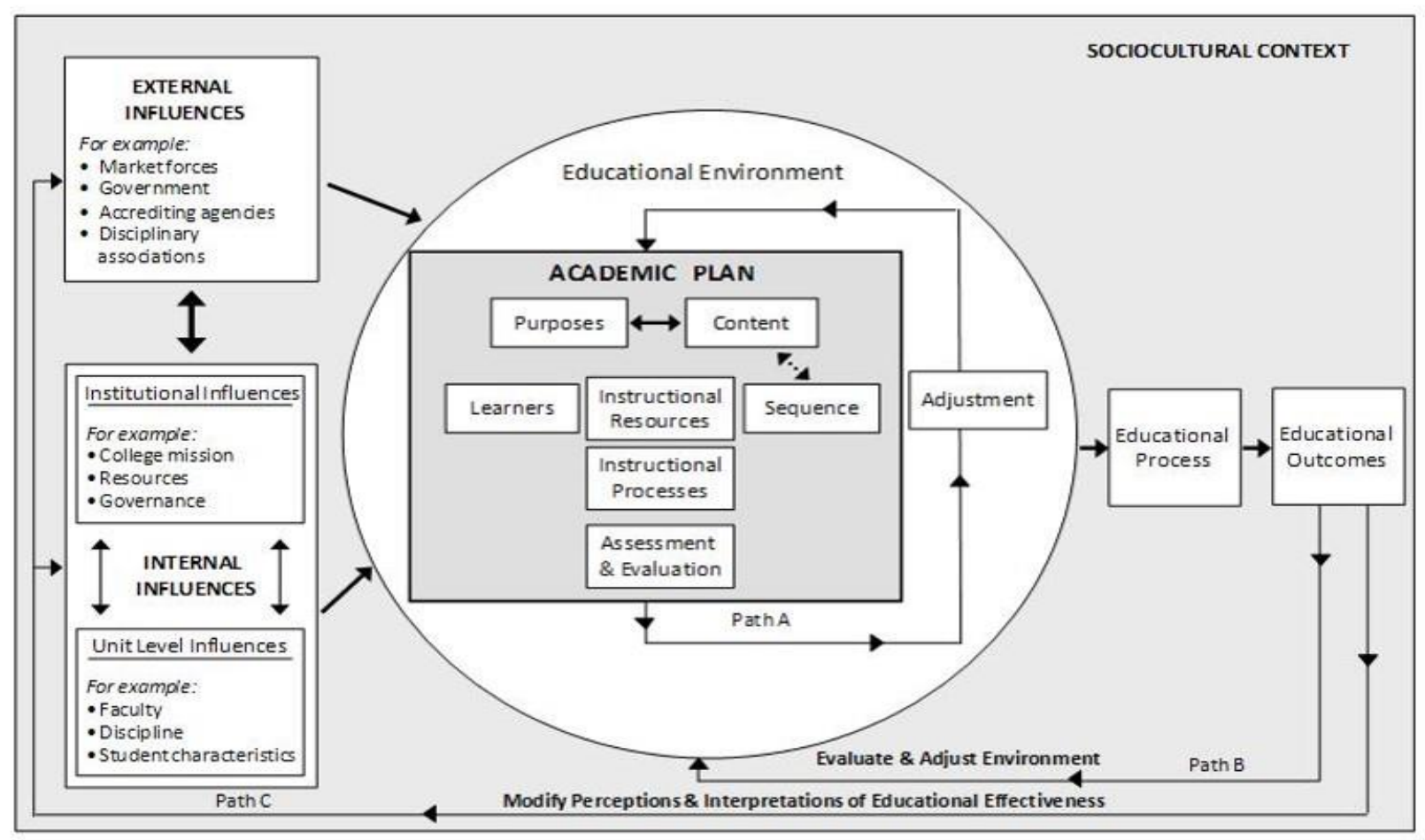

Figure 1. Lattuca and Stark's 2011 Academic Plans in Sociocultural Context Model ${ }^{6}$

The academic plan is meant to meet the needs and goals of multiple stakeholders, including students, faculty, college administration, and accrediting agencies. Assessment \& Evaluation measure the educational outcomes of an academic plan. Traditionally, this measurement is used to communicate educational outcomes to stakeholders, but assessment is also necessary to adjust the academic plan to meet the stated goals. When assessment is used for not only demonstrating educational outcomes, but also to inspire change to meet educational goals, this is known as "closing the loop." Spurlin et al. ${ }^{2}$ provide many definitions of the assessment process, as well as interrelated assessment cycles used for understanding engineering 
education, but we focus on assessment cycles as defined by Lattuca and Stark's model, shown as Paths A, B, and C in Figure 1. It is important to understand that, in this framework, while assessment may be used to evaluate performance of faculty and students, it is primarily for the purpose of continuous improvement of the academic plan. The following paragraphs describe the three pathways represented by Paths A, B, and C as "educational control loops" that adjust academic plans to effectively satisfy stakeholders' needs.

Path $A$ is the path of adjusting the academic plan within the educational environment. This may be instigated by self-study, perceptions of faculty, or assessment, among other factors. Assessment following this path is used to inform changes to the academic plan while not challenging larger systems in which the plan is set. One example of this would be restructuring the organization of the content of a class to better reflect the knowledge structures of experts, as is discussed by Ambrose, Bridges, DiPietro, Lovett, and Norman. ${ }^{8}$ Another, perhaps more typical, example is refining a section of a course in which students are not satisfactorily meeting educational objectives. The results and administration of an assessment may be grounds for changing not only the content, but the assessment itself so that it more accurately measures students' achievements. This path represents a significant portion of the adjustment described in this paper, in which we describe how the assessment instruments of the pilot of the IPM will be revised along with curricular practices.

However, without Path $B$, which adjusts the educational environment that surrounds an academic plan, there are limits to the degree to which academic plans can align with educational theory and stakeholder needs. In their study of science faculty implementing new practices, Henderson and Dancy ${ }^{9}$ developed a model that describes the interaction between instructors' individual conceptions about teaching and learning and the environment that instructors are situated in. They identify many situational barriers to changing instruction practices, including student attitudes towards school, lack of instructor time, and departmental norms. ${ }^{10-12}$ The environment in which an academic plan is implemented can be changed. Lewin's theories of cultural change describe a process of "unfreezing" and "refreezing" cultural fixtures, in order to make sustainable, lasting, deliberate influence on organizational processes. ${ }^{13}$ Change in the assessment of a course or program is a complex process, with many resistances to overcome, even when the new system is "obviously better" (Kerns \& Watson, as cited in Spurlin et al. ${ }^{2}$ ). However, assessment and evaluation can inspire and aid in changing educational environments. In the Pathways initiative, Virginia Tech is supporting faculty to enact changes that could contribute to a new institutional standard for general education, yet the design process still involves challenges common to cultural shifts, such as resistance to change.

Finally, following Path $C$, assessment can also affect internal and external factors outside of the immediate educational environment. Path $\mathrm{C}$, for example, includes assessment used to inform the community and encourage change through evidence-based teaching (e.g., see Borrego and Henderson for eight change strategies ${ }^{14}$ ). These change strategies, which include diffusion of innovative techniques and the enactment of new policy, influence the perceptions of those who participate in academic plans. Assessment is a key part of this process, in that it procures evidence in the form of educational outcomes affected by innovations in engineering education.

External factors that influenced the IPM academic plan included learning objectives and the related assessment rubrics from the Association of American Colleges and Universities 
(AAC\&U) VALUE Rubric project. ${ }^{15}$ In addition to easing the load on Virginia Tech faculty and administration for development of general education assessment, these rubrics were also intended to make it easier for Virginia Tech to satisfy external accrediting bodies, namely the Southern Association of Colleges and Schools. These learning objectives can also be mapped to ABET criterion as Bilén, Kisenwether, Rzasa, and Wise ${ }^{16}$ do for their faculty defined learning objectives. In addition to providing rubrics for assessment, AAC\&U also hosted workshops that highlight exemplary academic planning within our institution. Another external factor, market forces, pointed to the need for interdisciplinary, "well-rounded," and "T-shaped" students. ${ }^{17,18}$

In addition to these external factors, internal factors also played a significant role in the design of the minor. For example, pre-existing faculty relationships influenced which classes we selected as core classes and student characteristics influenced logistical decisions related to the minor (e.g., prerequisites, capstone requirements, marketing strategies).

\section{Interdisciplinarity and General Education}

While the Innovation Pathways Minor is housed in the College of Engineering, it is important to keep in mind that it is a general education minor created by an interdisciplinary team of faculty. Many of the courses are housed in other colleges or are cross-listed, and interdisciplinarity plays a key role in achieving the educational goals of the minor. Additionally, the general education goals of the minor are to achieve learning objectives that are broader than specialized disciplinary learning.

As Lattuca and Stark ${ }^{6}$ discuss, the process of developing an academic plan becomes complicated when it involves planners from many disciplines, as is the case in general education. Different departments and disciplines have different instruction and assessment strategies, resulting in variations along a continuum of instructor-centered or student-centered. ${ }^{19}$ Planning an interdisciplinary program requires compromise between many points of view. One way to accommodate students from multiple disciplines is offering multiple pathways that align with specific disciplines, as done by Bilén et al. ${ }^{16}$ in their design of an entrepreneurship minor. In this example, the designers broke their program into desired learning outcomes mapped to ABET objectives. In our case, we designed the IPM program by mapping to the university's liberal education learning objectives, while also incorporating our own desired outcomes.

The AAC\&U defines liberal education as an approach to learning that "empowers individuals," "prepares them to deal with complexity, diversity, and change," and "emphasizes a broad set of skills, and develops an underlying set of values." ${ }^{\text {20 }}$ Additionally, AAC\&U defines general education to be the part of a college's liberal education that all students are exposed to. A model for liberal education that is embraced by Virginia Tech is that of educating the "Tshaped" professional, ${ }^{21}$ where students develop broad competencies that span boundaries, in addition to deep content knowledge in at least one discipline. These broad, interdisciplinary, value-based aspects of liberal education are increasingly seen as a necessary aspect of educating engineers. ${ }^{1,22}$ The IPM uses innovation as a liberal education goal as well as a lens through which students can learn perspectives from engineering, business, industrial design, and science, technology and society as they construct their own general education pathways. ${ }^{23}$ 
As a content area, innovation is a relatively new academic focus. As part of the challenge of working across disciplines, the team addressed the fact that there is no single accepted definition of innovation. Some define innovation from an organizational perspective ${ }^{24}-$ as a necessary trait for an organization (corporation) to be sustainably productive and for that organization to produce disruptive technology. ${ }^{25}$ Others define innovation from an individual abilities standpoint - as the capacity for students to execute the known processes of innovators, at which point the focus is on self-efficacy. ${ }^{26}$ There are multiple ways of connecting individuals' innovation and creativity. Creativity has been roughly equated with innovation, ${ }^{27}$ and also seen as a separate but necessary ingredient for innovation. ${ }^{28}$ An interesting and useful insight into the definition of creativity is that there are multiple creativities. ${ }^{29,30} \mathrm{Craft}^{31}$ in her critiques of education for creativity, notes that creativity is context specific, and is defined by cultural values. Following these conceptions of creativity, our team aims to teach and assess "innovation" from multiple interdisciplinary perspectives (e.g., economics, social movements, personal pursuits).

However, we do use Baxter-Magolda's concept of Self-Authorship to guide our understanding of creativity and innovation. The Self-Authorship framework connects multiple dimensions of student development (cognitive, intrapersonal, and interpersonal) and describes the potential for individuals' awareness of and commitment to acting on their internally defined values. ${ }^{32}$ Self-Authorship has been shown as one potential pathway to creative ways of knowing in engineering ${ }^{33}$ and is also considered an important goal for liberal education. ${ }^{32}$ For a more indepth treatment of the connection between innovation and Self-Authorship in our development of the IPM, refer to Gewirtz, Davis, Benitez, and McNair. ${ }^{34}$

\section{Designing the IPM}

In their discussion of generating academic plans, Lattuca and Stark $^{6}$ distinguish between the design and planning of academic structures such as courses, programs, and even colleges themselves. Design of programs such as the IPM requires more deliberate decision-making and reference to frameworks than does planning. Although we did not have the luxury of designing the IPM from scratch, we worked to be intentional in every step of the minor development process. As described in the previous sections, we used the academic planning model (Figure 1) as a guide in what factors to consider throughout the design process. We were also intentional in the ways that we considered interdisciplinary within the minor and aware of both the benefits and challenges that result from such collaborations. With the goal of making the IPM available to students from all majors, we worked to build in flexibility for students from different disciplines to construct customized pathways. We also selected core classes that allowed for the continuation of preexisting relationships between faculty members and then determined which learning objectives were most likely to be satisfied by those classes. Finally, we considered the literature on education for innovation and creativity and sought to influence our design with innovation perspectives from multiple disciplines. 


\section{Methods}

This study used a case study approach to assess the Pathways minor format of general education. Focusing on the individual case of the IPM, we review our first iteration of assessing the three core courses for their corresponding general education outcomes. The goal of this first assessment cycle was to get a baseline or snapshot of where we are starting from. None of the courses were adjusted for alignment with the general education outcomes, rather, what we learned through this assessment will guide future adjustments before the minor is officially in place. This iteration focused at a program level (i.e., minor-level) assessment to identify whether the relevant general outcomes were being met at all. Our plan is that future iterations can assess at increasingly granular levels of detail, focusing on continuous improvement at the course and eventually at the assignment level.

In the fall semester of 2016, all three of the core courses for the IPM were being taught, so a basic assessment plan was devised to gather baseline data on the Pathways core and integrated outcomes that these courses are proposing to meet. A university committee developed a rubric for each of the core and integrated Pathways outcomes that describe the outcome in 3-5 indicators, of which a course is expected to meet a majority. The assessment plan identified specific assignments within the courses to be scored using these rubrics. Because the rubrics are still in development at the university level, we are not able to share them at this time. The assessment plan was developed through a collaboration between the assessment team and the course instructors. Each instructor determined which indicators they felt their class could meet and the assessment team helped select the assignments to assess and created a schedule to complete the assessment process. Each assignment was collected via a course management software and scored separately by two members of the research team. Each rubric identifies 3-5 indicators that the outcome is being met, and asks the reviewer to rank the assignment either 0 (Below Competent), 1 (Competent) or 2 (Above Competent) for each indicator. Table 2 outlines the types of assignments that were used to assess each of the required outcomes and the number of assignments that were assessed in each case.

Table 2. Assignments used to assess each Pathways outcome.

\begin{tabular}{|l|c|c|c|}
\hline \multicolumn{1}{|c}{ Outcomes } & $\begin{array}{c}\text { Innovation in Context } \\
\begin{array}{l}\text { Critical Thinking in } \\
\text { the Humanities }\end{array}\end{array}$ & $\begin{array}{c}\text { Final Project Presentation } \\
\text { (8 projects) }\end{array}$ & \\
\hline $\begin{array}{l}\text { Critique and } \\
\text { Practice in Design } \\
\text { \& Arts }\end{array}$ & & $\begin{array}{c}\text { Final Project } \\
\text { Report \& Presentation } \\
\text { (3 projects) }\end{array}$ & \\
\hline $\begin{array}{l}\text { Reasoning in the } \\
\text { Social Sciences }\end{array}$ & & & $\begin{array}{c}\text { Final Project Report } \\
\text { (11 projects) }\end{array}$ \\
\hline $\begin{array}{l}\text { Intercultural and } \\
\text { Global Awareness }\end{array}$ & & $\begin{array}{c}\text { Final Project Report \& } \\
\text { Presentation (3 projects) }\end{array}$ & \\
\hline Ethical Reasoning & $\begin{array}{r}\text { Consequences of Final } \\
\text { Project (27 essays) }\end{array}$ & & $\begin{array}{c}\text { Essay on Ethical } \\
\text { Implications of Final } \\
\text { Project (11 essays) }\end{array}$ \\
\hline
\end{tabular}




\section{Results}

The results of our initial round of assessment are presented here for each of the three core courses in the IPM. Each section contains the numerical scores achieved for each outcome as well as a short description of the course itself that may help the reader interpret the results. Numerical scores are presented as the number of students whose assignment was rated at each level $(0,1$, or 2$)$ for each indicator that was assessed. It is important to emphasize that, because these courses were not designed with these learning outcomes in mind and these rubrics were designed at the university level, the results presented may not accurately represent how well students learned or how well faculty members taught these concepts. The goal here was to test out the assessment process, get a baseline, and give feedback on the rubrics to the university Pathways committee.

\section{Innovation in Context}

Innovation in Context is a course based in the Liberal Arts College at Virginia Tech. The course's purpose is to explore what "innovation" means from a variety of perspectives. Students read scholarly work on the subject from different disciplines and participate in group discussions. Students also work in teams throughout the semester to research a particular innovation happening locally. Different assignments throughout the semester guide students in exploring their selected innovation, including one essay focused on the consequences or implications of the innovation. At the end of the semester, teams present a final analysis of the innovation they studied using the different perspectives they developed throughout the semester.

Innovation in Context was assessed for two learning outcomes. The general education outcome Critical Thinking in the Humanities was assessed by reviewing each group's final project presentation based on the three indicators listed in Table 3 below (lines 1-3). The resulting scores indicate that based on this assignment, the majority of students did not achieve this outcome through the Innovation in Context course. Ethical Reasoning was assessed using an individual assignment earlier in the semester where students discussed the potential consequences of the innovation their group was studying. The results for this outcome (lines 4 and 5 in Table 3) indicate similarly that students did not exhibit this outcome in the assignment we assessed.

Table 3. Assessment results for Innovation in Context

\begin{tabular}{|c|l|c|c|c|c|}
\hline $\begin{array}{c}\text { Learning } \\
\text { Outcome }\end{array}$ & $\begin{array}{c}\text { Learning } \\
\text { Indicator }\end{array}$ \\
\hline $\begin{array}{c}\text { Critical } \\
\text { analyze texts and other created } \\
\text { artifacts using theories and } \\
\text { methods of the humanities. }\end{array}$ & 28 & 21 & 7 & 0 \\
$\begin{array}{c}\text { Students } \\
\text { Humanities }\end{array}$ & $\begin{array}{l}\text { Interpret texts and other created } \\
\text { artifacts within multiple } \\
\text { historical, intellectual, and } \\
\text { cultural contexts. }\end{array}$ & 28 & 15 & 13 & 0 \\
\hline
\end{tabular}




\begin{tabular}{|c|c|c|c|c|c|}
\hline & $\begin{array}{l}\text { Synthesize multiple complex } \\
\text { sources and create a coherent } \\
\text { narrative or argument. }\end{array}$ & 28 & 25 & 0 & 3 \\
\hline \multirow[b]{2}{*}{$\begin{array}{l}\text { Ethical } \\
\text { Reasoning }\end{array}$} & $\begin{array}{l}\text { Identify ethical issues in a } \\
\text { complex context. }\end{array}$ & 27 & 18 & 7 & 2 \\
\hline & $\begin{array}{l}\text { Articulate and defend positions } \\
\text { on ethical issues in a way that is } \\
\text { both reasoned and informed by } \\
\text { the complexities of those } \\
\text { situations. }\end{array}$ & 27 & 24 & 3 & 0 \\
\hline
\end{tabular}

\section{Create!}

Create! is a course housed in the College of Engineering at Virginia Tech. The purpose of the course is to guide students through a process of creative inquiry and design that is interdisciplinary and collaborative. Several smaller course assignments combine into a larger semester-long design project that students complete in groups. The course begins with customer discovery and market analysis after which the students develop storyboards for their design idea. Students refine their ideas through multiple studio critique sessions where they give each other feedback and suggestions. The last step of this design process is a final presentation and report in which each team documents their final design as well as the process they followed to reach it.

Create! was assessed for the learning outcomes Critique and Practice in Design and the Arts and Intercultural and Global Awareness (results shown in Table 4). Both outcomes were assessed based on the final team presentations and reports at the end of the semester. The resulting scores for the first outcome reveal more variation in achievement across indicators than seen in the Innovation in Context course. It seems that some aspects of this learning outcome were covered better (i.e., lines 2 and 3 ) than others (i.e., line 1). However, the second learning outcome reflects a result similar to the Innovation in Context course in that the majority of the students did not achieve these indicators on the assignment assessed.

Table 4. Assessment results for Create!
Learning
Learning
\# of $\quad 0$ - Below
1 -
2 - Above
Outcome Indicator
Students Competent Competent Competent

\begin{tabular}{|c|l|c|c|c|c|}
\hline & $\begin{array}{l}\text { Apply interpretive strategies or } \\
\text { methodologies in design or the } \\
\text { arts. }\end{array}$ & 9 & 9 & 0 & 0 \\
\cline { 2 - 5 } $\begin{array}{c}\text { Critique and } \\
\text { Practice in } \\
\begin{array}{c}\text { Design and the } \\
\text { Arts }\end{array}\end{array}$ & $\begin{array}{l}\text { Employ skills, tools, and } \\
\text { methods of working in design } \\
\text { or the arts. }\end{array}$ & 9 & 0 & 9 & 0 \\
\cline { 2 - 5 } & $\begin{array}{l}\text { Produce a fully developed work } \\
\text { through iterative processes of } \\
\text { design or the arts. }\end{array}$ & 9 & 3 & 3 & 3 \\
\hline
\end{tabular}




\begin{tabular}{|c|l|c|c|c|c|}
\hline \multirow{2}{*}{$\begin{array}{c}\text { Intercultural } \\
\text { and Global } \\
\text { Awareness }\end{array}$} & $\begin{array}{l}\text { Interpret an intercultural } \\
\text { experience from both one's } \\
\text { own and another's worldview. }\end{array}$ & 9 & 9 & 0 & 0 \\
\cline { 2 - 5 } & $\begin{array}{l}\text { Address significant global } \\
\text { challenges and opportunities in } \\
\text { the natural and human world. }\end{array}$ & 9 & 6 & 3 & 0 \\
\hline
\end{tabular}

\section{StartUp}

Start $U p$ is a course that is cross-listed in three different colleges and departments. This course has the longest history of the three at Virginia Tech, having been offered in multiple departments in different forms before settling where it is today. The purpose of this course is to guide student teams through the customer discovery phase of technology commercialization. Students hear from local entrepreneurs, read books on entrepreneurship, and conduct market research following the Lean Startup Methodology for a potential product. Students refine their business model throughout the semester, including completion of a short essay on the ethical implications of their product. At the end of the semester, each team completes a final report describing their final product and explaining the development of their business model throughout the course of the semester.

StartUp was assessed for two Pathways learning outcomes (results shown in Table 5). Reasoning in the Social Sciences was assessed using the final reports produced by the student teams, and Ethical Reasoning was assessed using the ethical implications essay assignment. In contrast to Innovation in Context and Create!, these assessments revealed relatively good alignment with the learning outcomes. For Reasoning in the Social Sciences, the majority of the students achieved competency, with many students reaching the "above competent" rating. These results represent the best ratings on any learning outcome in this first round of assessing the IPM. The Ethical Reasoning assessment is not quite as impressive, although it does show some improvement over what we found in the first class on the same learning outcome. Half of the class achieved the first indicator (line 4), but very few achieved the second (line 5). Overall, however, Start Up revealed the closest alignment of any of the IPM courses with the general education outcomes that it is intended to meet.

Table 5. Assessment results for StartUp

\begin{tabular}{|c|l|c|c|c|c|}
$\begin{array}{c}\text { Learning } \\
\text { Outcome }\end{array}$ & \multicolumn{1}{|c}{$\begin{array}{c}\text { Learning } \\
\text { Indicator }\end{array}$} & $\begin{array}{c}\text { \# of } \\
\text { Students }\end{array}$ & $\begin{array}{c}\text { 0 - Below } \\
\text { Competent }\end{array}$ & 1 - & 2 - Above \\
the social sciences & $\begin{array}{l}\text { Identify fundamental concepts of } \\
\text { the }\end{array}$ & 50 & 9 & 31 & 10 \\
\cline { 2 - 6 } $\begin{array}{l}\text { Reasoning } \\
\text { in the Social } \\
\text { Sciences }\end{array}$ & $\begin{array}{l}\text { Analyze human behavior, social } \\
\text { institutions, and/or patterns of } \\
\text { culture using theories and methods } \\
\text { of the social sciences }\end{array}$ & 50 & 19 & 26 & 5 \\
\cline { 2 - 6 } & $\begin{array}{l}\text { Identify interconnections among } \\
\text { and differences between social } \\
\text { institutions, groups, and individuals }\end{array}$ & 50 & 14 & 21 & 15 \\
\hline
\end{tabular}




\begin{tabular}{|c|l|c|c|c|c|}
\hline \multirow{2}{*}{$\begin{array}{c}\text { Ethical } \\
\text { Reasoning }\end{array}$} & $\begin{array}{l}\text { ldentify ethical issues in a complex } \\
\text { context. }\end{array}$ & 50 & 27 & 23 & 0 \\
\cline { 2 - 5 } & $\begin{array}{l}\text { Articulate and defend positions on } \\
\text { ethical issues in a way that is both } \\
\text { reasoned and informed by the } \\
\text { complexities of those situations. }\end{array}$ & 50 & 45 & 0 & 5 \\
\hline
\end{tabular}

\section{Discussion}

The results reported above represent a baseline for how well the three IPM core courses align with the Pathways to General Education outcomes designed by the university. It is important to recall that none of the courses were designed with the specific outcomes in mind, and they also were not adjusted to improve alignment prior to this semester. Rather, we will use these results to inform adjustments for future semesters. As this round of assessment was designed to capture a snapshot, we did not set any specific goals as to how many students we wanted or expected to see fall into each level of learning outcome achievement. However, to focus our future work, we will discuss places where we see a majority of students achieving a 0 or "Below Competent" rating on an indicator as opportunities for improvement in our next iteration.

Before considering the opportunities for improvement in the courses, however, we want to discuss the weaknesses we saw in the rubrics themselves. First and foremost, we found the terminology of "Below Competent," "Competent," and "Above Competent" to be inappropriate when discussing specific student learning outcomes. The term "competence" in itself connotes a sum of competencies that "emphasizes the connection between a holistic complex of knowledge, skill, and motive, attitude, etc. and a job-fit under the specific work context". 35 There was a lot of nuance in the projects we were assessing, and having only three choices made it hard to choose where to rate each assignment. For example, there was a lot of variation within the "Below Competent" category - some students were much closer to "Competent" than others. The association of a score of 0 with "Below Competent" was also unfair, because it was not as though students had achieved no level of competence. As a result of completing our first round of assessment and experiencing these challenges with the rubrics, we will be submitting our feedback to the university Pathways committee with suggestions to improve the rubrics going forward.

While there were some challenges with the rubrics, we do believe that they provided some useful feedback to help us improve the IPM courses going forward. However, it is important for us not to make assumptions about why specific ratings were achieved, but consider each of the following possibilities:

1. Was the topic described in an indicator part of the course content? If not, should it be? Is this indicator appropriate to use in assessing this course?

2. Was the topic described in an indicator assessed by the assignment we selected? Is this a case where the topic was taught thoroughly but not assessed accurately?

3. Was the topic described in an indicator learned sufficiently/effectively in the course? Do we need to change how the topic is taught in the course? 
Any of these three scenarios could result in low scores on the learning outcome rubrics that might not accurately reflect actual learning experiences. We need to identify which one applies in each case for our action plan to lead to the improvement we want to see.

Our data provides examples of each of these three scenarios across the three courses. Indicators where all students fell into the "Below Competent" range tend to be the cases described by Scenario One above. These topics were not covered by the course at all, reflected in the fact that none of the students achieved the indicator. Examples of this can be seen most prominently in the Create! course, where two indicators fall into this category: the Critique and Practice in Design and the Arts indicator on "interpretive strategies and methodologies" and the Intercultural and Global Awareness indicator on "interpreting a intercultural experience from another's worldview." As an assessment team, our next steps with indicators in this category will be to discuss with the instructors of the course if they still feel that these indicators are good choices for assessing their course. If so, we will help them brainstorm what types of activities would help them introduce these topics in their courses. If not, we will consider what other indicators from the rubric might fit their course more accurately.

Cases where a few students achieved competence on an indicator, but the majority did not, could fall into either Scenario Two or Scenario Three described above. Because the assessment team had access to the assignment descriptions, we were able to consider whether they seemed to align with the indicators being assessed. Based on this, we suspect that some of our cases fall into Scenario Two above, mainly in the Innovation in Context course. For the Critical Thinking in the Humanities learning outcome, we assessed a final presentation for indicators that discuss "analyzing," "interpreting," and "synthesizing texts." Because we know the course did involve reading, discussing, and writing about a variety of texts, we believe that using a presentation rather than a written assignment may have been a mistake. While the final presentation is the most comprehensive project in the course, it did not communicate the depth of thought described by these indicators. To address this issue going forward, we will work with the course instructors to determine whether we should assess different assignments for this outcome, or whether it might be possible to incorporate a written component into the final project as was done in the other two courses.

We do not believe the assignment to be misaligned with the indicators that we find in Scenario Three. It is important to consider the first two options before jumping to this one to avoid some of the negative stigma associated with assessment. However, there are cases in our project where we believe that a topic may need to be taught more thoroughly in a course, and that it makes sense to do so given the goals of the course. Examples of this scenario can be found in each of the courses: "articulating and defending a stance on ethical issues" in both Innovation in Context and StartUp and "addressing significant global challenges" in Create!. It is interesting to note that this scenario is most common for indicators in the integrative outcomes, perhaps because instructors would not have focused on these as much in their initial design of the course. As we work with the instructors on these cases, we will emphasize the fact that these findings do not reflect negatively on them as instructors since they had not made any intentional effort to meet these indicators to begin with. It will be important to assure them that we are simply trying to help them better align with the Pathways indicators that they identified and not instruct them in how to run their courses. 
Stepping back to consider these results from a program level, we can see how our experiences fit into the model of an academic plan proposed by Lattuca and Stark. ${ }^{6}$ The design and creation of the IPM was the result of the internal influences from the university mission to construct Pathways minors. This influence included the definition of the general education learning outcomes that we sought to assess in our three core courses. Along with this influence came instructional resources, including funding for the graduate students who comprised the assessment team and the rubric used to complete the assessment. Our assessment process sought to measure the educational outcomes achieved in the three courses, ultimately feeding into the Paths A and B feedback loops in Figure 1. As discussed above, Path A feedback will take the form of discussions with faculty members about the results of our assessment and how that might impact future semesters of their courses. Path B feedback occurred when we submitted our assessment results (in the same format presented in this paper) to the Pathways to General Education team to inform their future planning. In this way, we are influencing the educational environment in which the IPM is situated, particularly as the Pathways program is still in development and making adjustments along the way. In time, the output of our future assessment cycles may also follow the Path $\mathrm{C}$ feedback loop as a method of informing the university about the educational effectiveness of the Pathways program, once it is fully functioning.

As we conclude our first iteration of the assessment cycle, we are beginning to set our goals for the next iteration. As discussed earlier, we are not trying to achieve perfection, but rather building in continuous improvement each time we run the courses. The first step for us will be to identify what our goals are in terms of assessment results. In an ideal world, every student would achieve "Above Competent" on every indicator, but in reality that is unlikely to happen. In realistic terms, then, what level of achievement will indicate to our team of faculty that the minor is succeeding at teaching these outcomes? This decision will be made by the IPM team as a whole, but perhaps might be something like "the majority of students achieve competency on all indicators." At a course level, we will also set specific goals for this round of assessment. We will identify specific indicators to focus on, likely those with the greatest room for improvement. As discussed earlier, this will involve individual discussions with the course instructors to help them understand what the results mean (i.e., discussing which of the three scenarios is likely represented) and identify strategies for how to improve moving forward. Ultimately, success in implementation and assessment of these diverse learning objectives serves to broaden the perspectives of students participating in the IPM, and brings us closer to our goal of forming "T-shaped" professionals.

\section{Implications for Engineering Education Professionals}

This paper introduces several interesting implications for engineering education professionals. From an academic planning perspective, we highlight here the implications of adding learning outcomes to a course after the course has been fully developed. It is clear that not following a "backwards design" process ${ }^{36}$ of identifying learning outcomes first can impact how well outcomes are achieved. At the same time, we recognize that in realistic academic planning situations, learning outcomes may change over time or be handed down from leadership (as is the case in our situation). Most significantly, it is critical for institutional initiatives to 
facilitate innovative work by faculty without using assessment in judgmental or restrictive ways. We describe the types of information that can be gained by assessing for learning outcomes even when a course has not been designed to meet them. Rather than attempt to redesign the courses immediately, by assessing first we believe that we have gained useful information about where to focus our efforts to support the progressive pedagogical work by faculty and achieve the greatest results that instructors will most likely adopt. Through our process, we also highlight the benefit of planning for continuous, incremental improvement through iterative assessment processes. Taking this approach to assessment can remove some of the stress associated with it, as it takes a realistic approach to how much can reasonably be changed each time a course is taught.

Beyond the assessment realm, our experiences in creating the IPM represent a unique experience in several ways. It is uncommon to have minors within a general education context or which span several departments. It is also rare for general education courses in general to be offered within engineering departments. As a result, putting an interdisciplinary general education minor through departmental and college level governance systems was not a straightforward process. Initial attempts to getting the Create! course approved in a department in the College of Engineering alerted the team to the fact that engineering departments may not be clear on how to approach general education courses. The college offers a relatively low number of courses that are widely open to the campus, a fact emphasized by the committee's question of why the first year engineering courses could not be listed as pre-requisites. Addressing confusion like this and trying to proactively communicate the goals and needs of a general education minor became a key part of the IPM team's strategy. A few steps that were taken along these lines were:

- Writing a memo introducing curriculum committee members to the Pathways program and the IPM specifically which was submitted with each course and minor proposal

- Asking for initial feedback from curriculum committee members before officially submitting the proposals and working to address their confusions and concerns

- Maintaining close contact with the Pathways leadership team and communicating roadblocks as soon as they became apparent

This unique experience, as described in this paper, may provide helpful insights for others seeking to introduce general education courses within a college or school of engineering. 


\section{References}

1. Heywood, J. Engineering at the crossroads: Implications for educational policy makers, in Cambridge Handbook of Engineering Education Research (eds. Johri, A. \& Olds, B. M.) 731-748 (Cambridge University Press, 2014).

2. Spurlin, J. E., Rajala, S. A. \& Lavelle, J. P. Assessing student learning, in Designing Better Engineering Education Through Assessment (eds. Spurlin, J. E., Rajala, S. A. \& Lavelle, J. P.) 23-58 (Stylus, 2008).

3. Suskie, L. Understanding the nature and purpose of assessment, in Designing Better Engineering Education Through Assessment (eds. Spurlin, J. E., Rajala, S. A. \& Lavelle, J. P.) 3-19 (Stylus, 2008).

4. Nersessian, N. J. \& Newstetter, W. C. Interdisciplinarity in engineering research and learning, in Cambridge Handbook of Engineering Education Research (eds. Johri, A. \& Olds, B. M.) 713-730 (Cambridge University Press, 2014).

5. Martin, T. et al. Discipline-based instruction to promote interdisciplinary design of wearable and pervasive computing products. Pers. Ubiquitous Comput. 17, 465-478 (2013).

6. Lattuca, L. R. \& Stark, J. S. Shaping the college curriculum: Academic plans in context. (Jossey-Bass, 2015).

7. Banta, T. W. \& Blaich, C. Closing the assessment loop. Change Mag. High. Learn. 43, 2227 (2011).

8. Ambrose, S. A., Bridges, M. W., DiPietro, M., Lovett, M. C. \& Norman, M. K. How learning works. (Jossey-Bass, 2010).

9. Henderson, C. \& Dancy, M. H. Barriers to the use of research-based instructional strategies: The influence of both individual and situational characteristics. Phys. Rev. Spec. Top. - Phys. Educ. Res. 3, 1-14 (2007).

10. Cech, E. A. \& Waidzunas, T. J. Navigating the heteronormativity of engineering: The experiences of lesbian, gay, and bisexual students. Eng. Stud. 3, 1-24 (2011).

11. McLoughlin, L. A. Spotlighting: Emergent gender bias in undergraduate engineering education. J. Eng. Educ. 94, 373-381 (2005).

12. Strayhorn, T. J. When race and gender collide: Social and cultural capital's influence on the academic achievement of African American and Latino males. Rev. High. Educ. 33, 307-332 (2010).

13. Schein, E. H. Kurt Lewin's change theory in the field and in the classroom : Notes toward a model of managed learning. Syst. Pract. 9, 27-47 (1996).

14. Borrego, M. \& Henderson, C. Increasing the use of evidence-based teaching in STEM higher education: A comparison of eight change strategies. J. Eng. Educ. 103, 220-252 (2014).

15. Association of American Colleges \& Universities. VALUE Rubric Development Project. (2016).

16. Bilén, S. G., Kisenwether, E. C., Rzasa, S. E. \& Wise, J. C. Developing and assessing students' entrepreneurial skills and mind-set. J. Eng. Educ. 94, 233-243 (2005).

17. Demirkan, H. \& Spohrer, J. T-shaped innovators: Identifying the right talent to support service innovation. Res.-Technol. Manag. 58, 12-15 (2015).

18. National Academy of Engineering. Engineering the future. (2008).

19. Lattuca, L. R., Bergom, I. \& Knight, D. B. Professional development, departmental contexts, and use of instructional strategies. J. Eng. Educ. 103, 549-572 (2014). 
20. Association of American Colleges \& Universities. What is a 21st century liberal education? (2016).

21. Brown, T. Strategy by design. Fast Company 95, 52-54 (2005).

22. Grasso, D., Burkins, M. B., Helble, J. J. \& Martinelli, D. Dispelling the myths of holistic engineering. Holist. Eng. Educ. Technol. 159-165 (2010). doi:10.1007/978-1-4419-13937_14

23. Collard, P. \& Looney, J. Nurturing creativity in education. Eur. J. Educ. 49, 348-364 (2014).

24. Baregheh, A., Rowley, J. \& Sambrook, S. Towards a multidisciplinary definition of innovation. Manag. Decis. 47, 1323-1339 (2009).

25. Morris, M. H., Avila, R. A. \& Allen, J. Individualism and the modern corporation: Implications for innovation and entrepreneurship. J. Manag. 19, 595-612 (1993).

26. Gerber, E. M., Martin, C., Kramer, E., Braunstein, J. \& Carberry, A. R. Developing an innovation self-efficacy survey. Presented at the 2012 IEEE Frontiers in Education, Seattle, WA (2012).

27. Lozano, F. \& Sabicer, A. Creativity and innovation: Building ecosystems to support risk taking, resiliency, and collaboration. Lib. Educ. 102, (2016).

28. Charyton, C. \& Merrill, J. A. Assessing general creativity and creative engineering design in first year engineering students. J. Eng. Educ. 98, 145-156 (2009).

29. Ferguson, D. M. \& Ohland, M. W. What is engineering inovativeness? Int. J. Eng. Educ. 28, 253-262 (2012).

30. Sternberg, R. J. Creativity or creativities? Int. J. Hum.-Comput. Stud. 63, 370-382 (2005).

31. Craft, A. The limits to creativity in education: Dilemmas for the educator. Br. J. Educ. Stud. 51, 113-127 (2003).

32. Baxter Magolda, M. B. \& King, P. M. Learning partnerships: Theory \& models of practice to educate for self-authorship. (Stylus, 2004).

33. Paretti, M. C., McNair, L. D. \& Gewirtz, C. Creativity and identity in the construction of professional portfolios, in Creative Ways of Knowing in Engineering (eds. Bairaktarova, D. \& Eodice, M.) 151-172 (Springer, 2017).

34. Gewirtz, C., Davis, K. A., Benitez, R. \& McNair, L. D. Self authorship and reflective practice in an innovation minor. Presented at the 2017 ASEE Annual Conference and Exposition, Columbus, OH (2017).

35. Kou, Y., Jia, Z. \& Wang, Y. A comparative research on competency and competence, in Proceedings of the Sixth International Conference on Management Science and Engineering Management: Focused on Electrical and Information Technology (eds. Jiuping Xu, M. Y. \& Lev, B.) 681-695 (Springer-Verlag, 2012).

36. Wiggins, G. \& McTighe, J. Understanding by design. (Assn. for Supervision \& Curriculum Development, 2005). 